\title{
Donor Heme Oxygenase-1 Promoter Gene Polymorphism Predicts Survival after Unrelated Bone Marrow Transplantation for High-Risk Patients
}

\author{
Tomohiro Horio $^{1,2}\left(\mathbb{D}\right.$, Eriko Morishita ${ }^{3}\left(\mathbb{D}\right.$, Shohei Mizuno ${ }^{1,2}\left(\mathbb{D}\right.$, Kaori Uchino ${ }^{1,2}$, \\ Ichiro Hanamura 1,2 , J. Luis Espinoza ${ }^{3}\left(\mathbb{D}\right.$, Yasuo Morishima ${ }^{4,5,6}$, Yoshihisa Kodera 2,4, \\ Makoto Onizuka ${ }^{7}$ (D), Koichi Kashiwase ${ }^{8}$, Takahiro Fukuda ${ }^{9}$, Noriko Doki ${ }^{10}$, \\ Koichi Miyamura ${ }^{11}$, Takehiko Mori ${ }^{12}$, Shinji Nakao ${ }^{13}$ and Akiyoshi Takami ${ }^{1,2, *(D)}$
}

1 Division of Hematology, Department of Internal Medicine, Aichi Medical University School of Medicine, Nagakute 480-1195, Japan; kuroro@aichi-med-u.ac.jp (T.H.); shohei@aichi-med-u.ac.jp (S.M.); ksakai@aichi-med-u.ac.jp (K.U.); hanamura@aichi-med-u.ac.jp (I.H.)

2 Hematopoietic Cell Transplantation Center, Aichi Medical University Hospital, Nagakute 480-1195, Japan; ykodera@river.ocn.ne.jp

3 Department of Clinical Laboratory Science, Kanazawa University School of Medical Sciences, Kanazawa 920-0942, Japan; eriko86@staff.kanazawa-u.ac.jp (E.M.); luis1.esp2.cd@outlook.com (J.L.E.)

4 Department of Promotion for Blood and Marrow Transplantation, Aichi Medical University School of Medicine, Nagakute 480-1195, Japan; ymorisim@aichi-cc.jp

5 Central Japan Cord Blood Bank, Seto 489-8555, Japan

6 Department of Hematology and Oncology, Nakagami Hospital, Okinawa 904-2195, Japan

7 Department of Hematology and Oncology, Tokai University School of Medicine, Isehara 259-1193, Japan; moni5@mac.com

8 Japanese Red Cross Kanto-Koshinetsu Block Blood Center, Tokyo 135-8521, Japan; k-kashiwase@ktks.bbc.jrc.or.jp

9 Hematopoietic Stem Cell Transplantation Unit, National Cancer Center Hospital, Tokyo 104-0045, Japan; tafukuda@ncc.go.jp

10 Hematology Division, Tokyo Metropolitan Cancer and Infectious Diseases Center Komagome Hospital, Tokyo 113-8677, Japan; n-doki@cick.jp

11 Department of Hematology, Japanese Red Cross Nagoya First Hospital, Nagoya 453-8511, Japan; k-miyamura@nagoya-1st.jrc.or.jp

12 Division of Hematology, Department of Medicine, Keio University School of Medicine, Tokyo 160-8582, Japan; tmori@a3.keio.jp

13 Department of Hematology, Faculty of Medicine, Institute of Medical, Pharmaceutical and Health Sciences, Kanazawa University, Kanazawa 920-8641, Japan; snakao8205@staff.kanazawa-u.ac.jp

* Correspondence: takami-knz@umin.ac.jp; Tel.: +81-561-62-3311; Fax: +81-561-63-3401

Received: 10 January 2020; Accepted: 10 February 2020; Published: 12 February 2020

check for updates

\begin{abstract}
Heme oxygenase-1 (HO-1), an intracellular enzyme that catalyzes the degradation of heme into biliverdin, free iron, and carbon monoxide, exerts anti-inflammatory and cytoprotective effects against endothelial cell injury. The HO-1 promoter gene has one important single-nucleotide polymorphism (SNP) rs2071746 (-413A > T) that is functional, and the A allele has been reported to be associated with higher HO-1 expression levels than the $\mathrm{T}$ allele. We investigated the influence of the HO-1 rs2071746 SNP on the transplant outcomes in 593 patients with hematological malignancies undergoing unrelated, human leukocyte antigen (HLA)-matched, T-cell-replete bone marrow transplantation (BMT) through the Japan Donor Marrow Program. In patients with high-risk diseases, the donor A/A or A/T genotype was associated with better 5 year overall survival ( $35 \%$ vs. $25 \% ; p=0.03$ ) and 5 year disease-free survival ( $35 \%$ vs. $22 \% ; p=0.0072)$, compared to the donor $\mathrm{T} / \mathrm{T}$ genotype. These effects were not observed in patients with low-risk diseases. The current findings therefore indicate that HO-1 rs2071746 genotyping could be useful for selecting donors and tailoring transplant strategies for patients with high-risk hematologic malignancies.
\end{abstract}


Keywords: HO-1; unrelated donor; bone marrow transplantation; single nucleotide polymorphism

\section{Introduction}

Allogeneic stem cell transplantation (allo-HSCT) is an important therapeutic option to cure advanced non-malignant and malignant hematologic diseases. However, its effectiveness has been limited by mortality and morbidity, due to transplant-related complications, such as conditioning regimen-related organ and tissue damage, severe infection, and graft-versus-host disease (GVHD). Several clinical and experimental studies [1-6] have shown that these complications, along with calcineurin inhibitors, activate and damage endothelial cells, potentially leading to organ dysfunction and subsequently multiorgan dysfunction syndrome. Thus, the modulation of endothelial cell injury could help to prevent or treat serious organ dysfunction after allo-HSCT.

Heme oxygenase-1 (HO-1), also known as a $32 \mathrm{kDa}$ heat-shock protein, is an intracellular enzyme that catalyzes the degradation of heme into biliverdin, ferrous iron, and carbon monoxide (CO), with biliverdin being subsequently catabolized into bilirubin [7-11]. HO-1 is highly induced in response to various stress signals, such as free heme and hemoglobin, inflammatory cytokines, ischemia, endotoxins, irradiation, and mucosal damage [9-16]. HO-1 thus exerts cytoprotective effects on endothelial cells through ant-oxidative, anti-inflammatory, anti-apoptotic, and anti-thrombotic effects, which are coordinated with heme metabolites of $\mathrm{CO}$ and bilirubin.

The HO-1 gene, also called the HMOX1 gene, is mainly expressed in monocytes/macrophages, natural killer cells, endothelial cells, and the heart [17]. One important single nucleotide polymorphism (SNP) in the promoter region of the HO-1 gene, rs2071746 (-413A > T), is functional, and the major A allele is reported to be associated with higher expression of HO-1 than the minor T allele [18,19]. There is growing evidence to support that non-human leukocyte antigen (HLA) genetic polymorphism represents a significant determinant of outcomes after allo-HSCT [20-26]. These findings prompted us to investigate the impact of the rs2071746 SNP in the HO-1 gene on the clinical outcomes of patients undergoing allogeneic bone marrow transplantation (BMT), using an HLA allele-matched, unrelated donor through the Japan Marrow Donor Program (JMDP).

\section{Results}

\subsection{The Frequencies of HO-1 Genotypes}

The HO-1 rs2071746 SNP was analyzed in 593 HLA-A, -B, -C, -DRB1, -DQB1, and -DPB1 allele-matched, unrelated BMT donor-transplant recipient pairs (Table 1). Based on the disease status and other risk factors that influence post-transplant outcomes, as previously reported [22,27-29], standard-risk disease was defined as acute myeloid leukemia (AML), acute lymphoblastic leukemia (ALL), or multiple myeloma (MM) in the first complete remission; malignant lymphoma (ML) in any complete remission; or myelodysplastic syndrome (MDS) or chronic myeloid leukemia (CML) in the chronic phase. Both ALL and AML, which were in the second complete remission, were included in the high-risk group, according to recent reports $[27,29]$ indicating that patients with AML and ALL in the second complete remission have worse post-transplant outcomes than those in the first complete remission. All other conditions were classified as high-risk disease. The genotype frequencies of $\mathrm{A} / \mathrm{A}$, $\mathrm{A} / \mathrm{T}$, and $\mathrm{T} / \mathrm{T}$ were $21 \%, 52 \%$, and $27 \%$, respectively, in recipients, and $23 \%, 52 \%$, and $25 \%$ in donors. These results were in accordance with the Hardy-Weinberg equilibrium $(p=0.49)$, and were similar to the HapMap data in the Japanese population ( $27 \%, 50 \%$, and $23 \%$, respectively) [30]. 
Table 1. Characteristics and heme oxygenase-1 (HO-1) genotypes of recipients and donors, according to the disease risk.

\begin{tabular}{|c|c|c|c|c|}
\hline \multirow{2}{*}{ Variable } & All & High-Risk & Standard-Risk & \\
\hline & Value & Value & Value & $p$ \\
\hline Number of cases & 593 & 232 & 361 & \\
\hline Recipient age, years, median (range) & $33(1-67)$ & $34(1-67)$ & $34(1-65)$ & \\
\hline Donor age, years, median (range) & $34(20-57)$ & $34(21-50)$ & $34(20-57)$ & \\
\hline Year of HSCT, median (range) & 2000 (1993-2007) & $2000(1993-2007)$ & $2000(1993-2007)$ & \\
\hline Recipient HO-1 genotype, $n(\%)$ & & & & 0.03 \\
\hline $\mathrm{A} / \mathrm{A}$ & $125(21)$ & $40(17)$ & $85(24)$ & \\
\hline $\mathrm{A} / \mathrm{T}$ & $306(52)$ & $135(58)$ & $171(47)$ & \\
\hline $\mathrm{T} / \mathrm{T}$ & $162(27)$ & $57(25)$ & $105(29)$ & \\
\hline Donor HO-1 genotype, $n(\%)$ & & & & 0.96 \\
\hline $\mathrm{A} / \mathrm{A}$ & $134(23)$ & $51(22)$ & $83(23)$ & \\
\hline $\mathrm{A} / \mathrm{T}$ & $308(52)$ & $122(53)$ & $186(52)$ & \\
\hline $\mathrm{T} / \mathrm{T}$ & $151(25)$ & $59(25)$ & $92(25)$ & \\
\hline Recipient sex, $n(\%)$ & & & & 0.55 \\
\hline Male & $352(59)$ & $134(58)$ & $218(60)$ & \\
\hline Female & $241(41)$ & $98(42)$ & $143(40)$ & \\
\hline Donor sex, $n(\%)$ & & & & 0.43 \\
\hline Male & $374(63)$ & $142(61)$ & $232(64)$ & \\
\hline Female & $218(37)$ & $90(39)$ & $128(36)$ & \\
\hline Recipient/Donor sex match, $n(\%)$ & & & & 0.54 \\
\hline Sex-matched & 387 (65) & $158(68)$ & $229(64)$ & \\
\hline Female/Male & $114(19)$ & $41(18)$ & $73(20)$ & \\
\hline Male/Female & $92(16)$ & $33(14)$ & $59(16)$ & \\
\hline Disease, $n(\%)$ & & & & 0.01 \\
\hline AML & $197(33)$ & $112(48)$ & $85(24)$ & \\
\hline ALL & 145 (24) & $72(31)$ & $73(20)$ & \\
\hline MDS & $82(14)$ & $0(0)$ & $82(23)$ & \\
\hline ML & $64(11)$ & $29(13)$ & $35(9)$ & \\
\hline CML & $101(17)$ & $16(7)$ & $85(24)$ & \\
\hline MM & $4(1)$ & $3(1)$ & $1(0)$ & \\
\hline ABO matching, $n(\%)$ & & & & 0.97 \\
\hline ABO-matched & $359(61)$ & $137(59)$ & $222(62)$ & \\
\hline Major mismatch & 115 (19) & $46(20)$ & 69 (19) & \\
\hline Minor mismatch & $95(16)$ & $40(17)$ & $55(15)$ & \\
\hline Bidirectional & $16(3)$ & $6(3)$ & $10(3)$ & \\
\hline Missing & $8(1)$ & $3(1)$ & $5(1)$ & \\
\hline Conditioning regimen, $n(\%)$ & & & & 0.86 \\
\hline Myeloablative & $517(87)$ & $204(88)$ & $313(87)$ & \\
\hline Reduced intensity & 69 (12) & $26(11)$ & $43(12)$ & \\
\hline Missing & $7(1)$ & $2(1)$ & $5(1)$ & \\
\hline Pretransplantation CMV serostatus, $n(\%)$ & & & & 0.23 \\
\hline CMV-positive recipient & $373(63)$ & $142(61)$ & $231(64)$ & \\
\hline CMV-negative recipient & $102(17)$ & $36(16)$ & $66(18)$ & \\
\hline Missing & $118(20)$ & $54(23)$ & $64(18)$ & \\
\hline $\mathrm{TNC}, \times 10^{8} / \mathrm{kg}$, median (range) & $7.7(0.1-259)$ & $7.7(0.1-79.1)$ & $7.7(0.6-259)$ & \\
\hline
\end{tabular}

Abbreviations: AML, acute myeloid leukemia; ALL, acute lymphoblastic leukemia; MDS, myelodysplastic syndrome; ML, malignant lymphoma; CML, chronic myeloid leukemia; MM, multiple myeloma; HSCT, hematopoietic stem cell transplant; $\mathrm{ABO}$, the "ABO" blood system; $\mathrm{CMV}$, cytomegalovirus; $\mathrm{TNC}$, total number of nucleated cells harvested.

\subsection{Transplant Outcomes According to the HO-1 Genotype}

The analysis on the influence of the $\mathrm{HO}-1$ on clinical outcomes after transplantation was stratified into standard-risk and high-risk disease groups to account for its prognostic significance. In the high-risk disease group $(n=232)$, the donor $\mathrm{A} / \mathrm{A}$ or $\mathrm{A} / \mathrm{T}$ genotype was associated with significantly better 5 year overall survival (OS; 35\% vs. 25\%, $p=0.033$; Figure 1A) and significantly better 5 year disease-free survival (DFS; $35 \%$ vs. $22 \%, p=0.0072$; Figure 1B), compared to the donor T/T genotype. There were no significant differences between the donor A/A or A/T genotype and the donor $\mathrm{T} / \mathrm{T}$ genotype with regard to the rates of relapse, transplant-related mortality (TRM), and graft-versus-host 
disease (GVHD; see Tables S1 and S2). In the standard-risk disease group $(n=361)$, the donor genotype had no significant effect on the transplant outcomes (see Tables S1 and S2, Figure S1). The recipient genotype had no significant effects on the transplant outcomes regardless of the disease risk (see Tables S1 and S2).

A OS in patients with high-risk disease

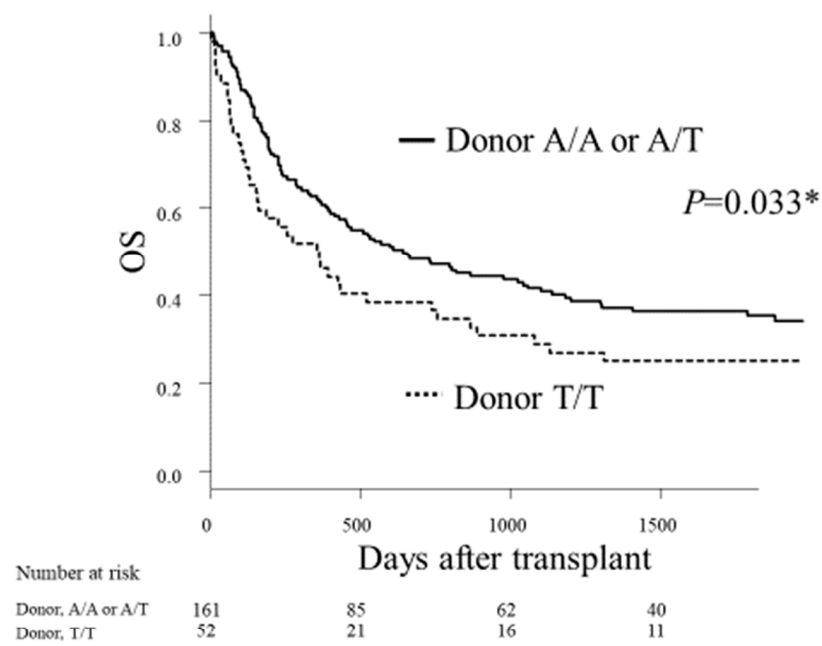

B DFS in patients with high-risk disease

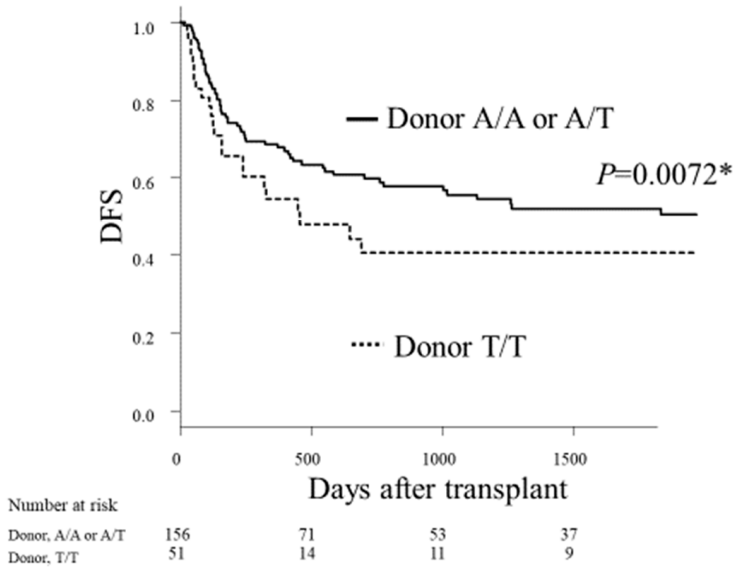

Figure 1. The Kaplan-Meier analysis of the overall survival (OS) rates (A) and the disease-free survival (DFS) rates (B) after transplantation, according to the donor HO-1 genotype in patients with high-risk disease. Solid lines represent the donor A/A or A/T genotype. Dashed lines represent the donor T/T genotype. An asterisk $\left(^{*}\right)$ denotes statistical significance $(p<0.05)$.

\subsection{Multivariate Analysis}

Multivariate analyses were performed by adjusting for the cofounding variables, such as recipient, donor, and transplant characteristics, the details of which are described in Section 4.3. In the high-risk disease group, the donor A/A or A/T genotype showed significantly better 5 year DFS (hazard ratio $(\mathrm{HR})=0.64 ; 95 \%$ confidence interval $(\mathrm{CI})=0.44-0.93 ; p=0.019$; Table 2$)$ and tended to show better 5 year OS ( $\mathrm{HR}=0.72 ; 95 \% \mathrm{CI}=0.50-1.04 ; p=0.082)$ compared to the donor $\mathrm{T} / \mathrm{T}$ genotype. In the standard-risk disease group, the donor genotype had no significant effect on the DFS or OS. The donor HO-1 genotype showed no significant effects on the TRM or GVHD rates in the multivariate analysis (Tables 2 and 3). The recipient HO-1 genotype did not significantly influence the transplant outcomes. 
Table 2. The results of the multivariate analysis of the association between the HO-1 genotype and the clinical outcomes after transplantation (first part).

\begin{tabular}{|c|c|c|c|c|c|c|c|c|c|c|c|c|}
\hline \multirow{2}{*}{ Variable } & \multicolumn{3}{|c|}{ OS } & \multicolumn{3}{|c|}{ DFS } & \multicolumn{3}{|c|}{ TRM } & \multicolumn{3}{|c|}{ Relapse } \\
\hline & HR & $95 \% \mathrm{CI}$ & $p$ & HR & $95 \% \mathrm{CI}$ & $p$ & HR & $95 \% \mathrm{CI}$ & $p$ & HR & $95 \% \mathrm{CI}$ & $p$ \\
\hline \multicolumn{13}{|l|}{ High-risk disease } \\
\hline Donor HO-1 genotype, A/T or A/A vs. T/T & 0.72 & $0.50-1.04$ & 0.08 & 0.64 & $0.44-0.93$ & 0.02 & 0.66 & $0.36-1.19$ & 0.16 & 0.83 & $0.51-1.35$ & 0.44 \\
\hline Recipient $H O-1$ genotype, $\mathrm{A} / \mathrm{T}$ or A/A vs. T/T & 0.91 & $0.62-1.32$ & 0.61 & 0.99 & $0.68-1.45$ & 0.98 & 1.03 & $0.57-1.85$ & 0.92 & 0.99 & $0.60-1.64$ & 0.98 \\
\hline Recipient age & 0.99 & $0.97-0.99$ & 0.004 & 0.99 & $0.98-1.00$ & 0.02 & 0.98 & $0.96-0.99$ & 0.006 & & & \\
\hline \multicolumn{13}{|l|}{ Standard-risk disease } \\
\hline Donor HO-1 genotype, A/T or A/A vs. T/T & 1.05 & $0.71-1.54$ & 0.80 & 0.91 & $0.56-1.47$ & 0.70 & 1.04 & $0.59-1.82$ & 0.89 & 0.71 & $0.40-1.22$ & 0.20 \\
\hline Recipient $H O-1$ genotype, $\mathrm{A} / \mathrm{T}$ or $\mathrm{A} / \mathrm{A}$ vs. T/T & 1.39 & $0.93-2.08$ & 0.10 & 1.30 & $0.79-2.17$ & 0.28 & 1.15 & $0.66-2.00$ & 0.62 & 1.41 & $0.76-2.63$ & 0.28 \\
\hline Recipient age & 0.97 & $0.96-0.98$ & $<0.001$ & 1.00 & $0.97-1.01$ & 0.24 & 0.96 & $0.94-0.98$ & 0.11 & 0.91 & $0.56-1.47$ & 0.70 \\
\hline Donor age & & & & & & & 0.97 & $0.94-1.01$ & 0.11 & 1.33 & $0.80-2.22$ & 0.27 \\
\hline CMV-positive recipient & 1.22 & $0.77-1.92$ & 0.39 & 0.58 & $0.36-0.94$ & 0.03 & 0.47 & $0.26-0.82$ & 0.008 & & & \\
\hline $\mathrm{ABO}$ major mismatch & & & & & & & 1.04 & $0.54-200$ & 0.90 & & & \\
\hline $\mathrm{ABO}$ minor mismatch & 0.59 & $0.39-0.88$ & 0.01 & & & & 0.50 & $0.28-0.89$ & 0.02 & & & \\
\hline $\mathrm{ABO}$ bidirectional & & & & & & & 13513.5 & $5555.6-333$ & .30 .001 & & & \\
\hline Male donor/female recipient & & & & & & & & & & 1.00 & $0.58-1.75$ & 0.99 \\
\hline Female donor/male recipient & & & & 2.27 & $1.05-5.00$ & 0.04 & & & & 2.22 & $1.03-4.76$ & 0.04 \\
\hline
\end{tabular}

Abbreviations: TRM, transplant-related mortality; HR, hazard ratio; CI, confidence interval; HSCT, hematopoietic stem cell transplant.

Table 3. The results of the multivariate analysis of the association between the HO-1 genotype and the clinical outcomes after transplantation (second part).

\begin{tabular}{|c|c|c|c|c|c|c|c|c|c|}
\hline \multirow[t]{2}{*}{ Variable } & \multicolumn{3}{|c|}{$\begin{array}{c}\text { Grades 2-4 } \\
\text { acute GVHD }\end{array}$} & \multicolumn{3}{|c|}{$\begin{array}{c}\text { Grades 3-4 } \\
\text { acute GVHD }\end{array}$} & \multicolumn{3}{|c|}{$\begin{array}{l}\text { Chronic } \\
\text { GVHD }\end{array}$} \\
\hline & HR & $95 \% \mathrm{CI}$ & $p$ & HR & $95 \% \mathrm{CI}$ & $p$ & HR & $95 \% \mathrm{CI}$ & $p$ \\
\hline \multicolumn{10}{|l|}{ High-risk disease } \\
\hline Donor $\mathrm{HO}-1$ genotype, $\mathrm{A} / \mathrm{T}$ or $\mathrm{A} / \mathrm{A}$ vs. $\mathrm{T} / \mathrm{T}$ & 1.10 & $0.61-1.96$ & 0.76 & 1.03 & $0.41-2.78$ & 0.88 & 0.91 & $0.51-1.59$ & 0.72 \\
\hline Recipient $\mathrm{HO}-1$ genotype, $\mathrm{A} / \mathrm{T}$ or $\mathrm{A} / \mathrm{A}$ vs. $\mathrm{T} / \mathrm{T}$ & 1.09 & $0.62-1.92$ & 0.76 & 1.00 & $0.40-2.50$ & 1.00 & 0.63 & $0.37-1.08$ & 0.09 \\
\hline \multicolumn{10}{|l|}{ Recipient age } \\
\hline \multicolumn{10}{|l|}{ Donor age } \\
\hline Conditioning regimen, MAC vs. RIC & 3.03 & $0.94-10.0$ & 0.06 & & & & & & \\
\hline TNC & 0.99 & $0.97-1.01$ & 0.23 & & & & & & \\
\hline Year of HSCT & 0.59 & $0.35-0.98$ & 0.04 & & & & 0.97 & $0.94-1.00$ & 0.10 \\
\hline \multicolumn{10}{|l|}{ Standard-risk disease } \\
\hline Donor $H O-1$ genotype, $\mathrm{A} / \mathrm{T}$ or $\mathrm{A} / \mathrm{A}$ vs. $\mathrm{T} / \mathrm{T}$ & 0.79 & $0.61-1.02$ & 0.07 & 1.19 & $0.56-2.50$ & 0.66 & 0.98 & $0.68-1.41$ & 0.91 \\
\hline Recipient $H O-1$ genotype, $\mathrm{A} / \mathrm{T}$ or $\mathrm{A} / \mathrm{A}$ vs. $\mathrm{T} / \mathrm{T}$ & 1.09 & $0.80-1.47$ & 0.60 & 1.96 & $0.85-4.35$ & 0.11 & 1.00 & $0.70-1.41$ & 1.00 \\
\hline Recipient age & & & & & & & 0.99 & $0.97-1.00$ & 0.02 \\
\hline CMV-positive recipient & 1.49 & $1.16-1.92$ & 0.002 & & & & & & \\
\hline Year of HSCT & & & & & & & 1.61 & $1.14-2.27$ & 0.008 \\
\hline
\end{tabular}

Abbreviations: GVHD, graft-versus-host disease; MAC, myeloablative conditioning; RIC, reduced-intensity conditioning; TNC, total nucleated cell count harvested. 


\subsection{Main Causes of Death}

When the main causes of death were analyzed according to the HO-1 genotype, although the donor $\mathrm{A} / \mathrm{A}$ or $\mathrm{A} / \mathrm{T}$ genotype showed relatively low cumulative incidence of fatal infection in the high-risk disease group ( $12 \%$ vs. $19 \%, p=0.19$; Figure 2$)$, there were no statistically significant differences.

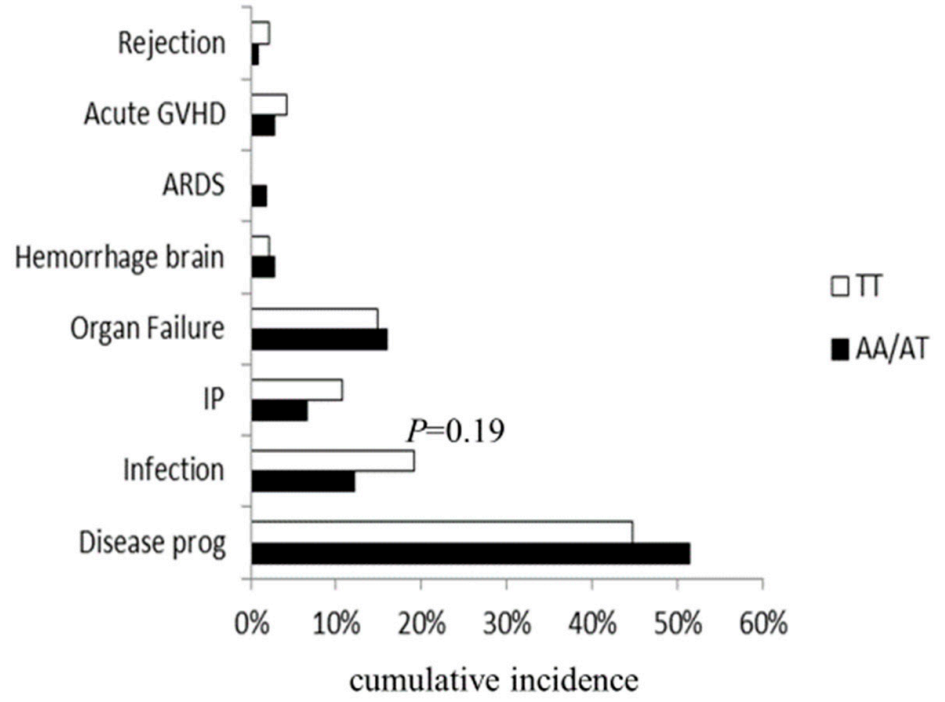

Figure 2. Main causes of death after transplantation, according to the donor HO-1 genotype in patients with high-risk disease. ARDS: acute respiratory distress syndrome; IP: interstitial pneumonia; disease prog: disease progression.

\section{Discussion}

The current study showed that the donor A/A or A/T genotype of the HO-1 rs2071746 promoter SNP was associated with better DFS than the donor T/T genotype in patients with high-risk hematologic malignancies who received unrelated, HLA-matched BMT through the JMDP. Of note, individuals with the HO-1 rs2071746 A allele have been suggested to have higher promoter activity, which induces higher expression levels of HO-1 compared to those without the A allele [18,19], thus suggesting that donor-derived HO-1 may have beneficial effects on survival after allo-BMT. This is the first report to demonstrate that the HO-1 SNP may be involved in the survival outcomes after allo-HSCT.

The mechanisms through which the donor HO-1 A/A or A/T genotype (plausibly associated with the higher inducibility of HO-1) exerts its beneficial effects remains to be determined. HO-1 is only marginally produced in the resting state, but is rapidly and highly induced in response to various oxidative stresses (e.g., organ and tissue damage and infection), and acts as an anti-inflammatory and cytoprotective protein [7,9-11,15,31,32]. Evidence of HO-1 induction improving the survival outcomes after allo-HSCT has been demonstrated in previous studies using mouse models [31,33]. It was shown that the induction of HO-1 reduced serum levels of proinflammatory cytokines, prevented damage to the intestinal mucosa and subsequent bacterial invasion, and improved overall survival after allo-HSCT [33]. Another study [31], in which transplantation was performed from HO-1 wild-type mice to HO-1 knockout mice, revealed that donor macrophages play pivotal roles in the recovery of the HO-1 function after allo-HSCT. In humans, HO-1 deficiency is associated with a distinctive feature: oxidative stress induces severe endothelial cell damage [10]. Vascular endothelial cell injury after allo-HSCT can potentially cause thrombotic microangiopathy, sinusoidal obstruction syndrome, capillary leak syndrome, and acute lung injury, leading to end-organ dysfunction [1-6]. These findings suggest that while organ and tissue damage from the conditioning regimen, infections, GVHD, and calcineurin inhibitors cause oxidative stress, which damages endothelial cells, the same can activate donor macrophages to produce $\mathrm{HO}-1$, protecting against endothelial cell injury and subsequently preventing organ dysfunction. BMT from donors with the HO-1 A/A or A/T genotype may be 
associated with improved survival outcomes in recipients by enhancing the beneficial effects of HO-1. However, this hypothesis is highly speculative, because the current study could not provide information on the inducibility of $\mathrm{HO}-1$ or the degree of organ and endothelial cell damage, according to the HO-1 genotype.

Further evidence that the HO-1 rs2071746 A/A or A/T genotype has the advantage of maintaining the organ function by protecting endothelial cells against oxidative stress may be seen in previous reports [18,19], which have shown that the HO-1 rs2071746 A/A genotype was associated with a reduced incidence of ischemic heart disease compared to the $\mathrm{A} / \mathrm{T}$ or $\mathrm{T} / \mathrm{T}$ genotypes in the Asian adult population, and that the donor HO-1 rs2071746 A/A or A/T genotype was associated with better graft survival and a better liver function after liver transplantation compared to the donor $\mathrm{T} / \mathrm{T}$ genotype in the European adult population. On the other hand, one report noted that the HO-1 rs2071746 $\mathrm{A} / \mathrm{A}$ and $\mathrm{A} / \mathrm{T}$ genotypes were associated with an increased incidence of acute kidney injury in the American infant population [34]. A plausible reason for this discrepancy may be the negative effect of hyperbilirubinemia, which possibly results from the higher inducibility of the HO- 1 genotype (A/A or A/T) in neonates. Further studies using additional cohorts are needed to better understand this discrepancy.

Recent reports [35-37] have suggested that the overexpression of HO-1 may promote the progression and relapse of various blood cancers, especially CML, as well as carcinogenesis, progression, and resistance to therapy in solid cancers. Unlike these observations, in the present study, the donor HO-1 A/A or A/T genotype (plausibly associated with the higher inducibility of HO- 1 ) was associated with better survival outcomes without increasing the risk of disease relapse after allo-HSCT in patients with high-risk patients. However, allo-HSCT can exert a robust graft-versus-leukemia (GVL) effect [38], which may eliminate the adverse effect associated with the higher HO-1 inducibility to potentially to promote progression and relapse. This hypothesis may be supported by the current findings that post-transplant progression and relapse rates in patients with CML were comparable between the donor HO-1 A/A or A/T genotype vs. the donor HO-1 T/T genotype, with 33\% vs. 33\% $(p=0.82)$ in the high-risk group, and $21 \%$ vs. $42 \%(p=0.14)$ in the standard-risk group. Studying the blood samples of donors and recipients would be useful for testing this hypothesis and defining the functional roles of the HO-1 SNP in post-transplant survival and relapse. Unfortunately, no blood samples of donors or recipients were available in the present study, and the functional roles of $\mathrm{HO}-1$ on post-transplant outcomes cannot be clarified.

It has been proposed that a higher HO-1 expression level prevents the progression of GVHD and acts prophylactically on sinusoid obstruction syndrome (SOS), while promoting relapse [39-41]. Although the results of this study suggest that the higher expression of HO- 1 is associated with favorable survival outcomes after allo-HSCT, the higher expression of HO-1 has not been shown to affect the risk of disease relapse or the development of GVHD. Furthermore, this cohort did not include information on the incidence of SOS, so the association between HO-1 and SOS is unknown. A plausible explanation for these differences may be due to the fact that the higher expression of HO-1-which was derived from the donor, not from the patient-appeared to influence the better survival outcomes after allo-HSCT. Namely, HO-1 derived from the vascular endothelium may be involved in the suppression of GVL effects and GVHD development, whereas HO-1 derived from donor blood cells may be mainly responsible for its anti-inflammatory and cytoprotective effects, leading to the prevention of organ damage. However, contrary to this hypothesis, a recent report from Denmark [39] showed that higher HO-1 expression derived from the donor may be associated with a higher risk of relapse after allo-HSCT, based on an investigation of the $(G T)_{n}$ repeat in the promotor region of donors and recipients receiving allo-HSCT. Differences between the Japanese and Danish ethnic groups might account for the role of $\mathrm{HO}-1$ in the induction of the GVL effect. These hypotheses are highly speculative and need to be clarified by future research.

In this study, the beneficial effects of the donor HO-1 A/A or A/T genotype were only observed in patients with high-risk diseases, and not in those with standard-risk diseases. Although it is 
unclear what causes this difference, patients with high-risk diseases are often heavily treated in an attempt to achieve remission, and may potentially be prone to endothelial cell damage, which may increase the importance of HO-1 in post-transplant survival. This hypothesis may be supported by previous reports showing that an advanced disease status was associated with an increased risk of endothelial cell damage, such as sinusoidal obstruction syndrome and thrombotic microangiopathy, after allo-HSCT [42,43].

One major limitation of this study is the lack of results that conclude the functional roles of the HO-1 SNP in survival outcomes after BMT. The association of the surrogate markers for endothelial cell damage after allo-HSCT, such as serum levels of angiopoietin 2 and thrombomodulin [44], with the HO-1 SNP may offer useful information on this issue. Unfortunately, no serum samples were available in the present study. A second major limitation of this study is that information on transplant-associated thrombotic microangiopathy (TAM) resulting from endothelial cell damage was also unavailable. A study to examine whether the HO-1 genotype and its expression levels contribute to the development of post-transplant complications (e.g., TAM, organ damage, and GVHD) and the graft-versus-tumor effect is warranted.

\section{Materials and Methods}

\subsection{Patients}

The HO-1 rs2071746 genotypes were determined on 593 recipients with hematological cancers who underwent transplant via the JMDP with T-cell-replete marrow from HLA-A, -B, -C, -DRB1, -DQB1, and -DPB1 allele-matched donors between January 1993 and December 2007, as well as their unrelated bone marrow donors. The HLA genotyping of recipients and donors was performed by the Luminex microbead method, as described previously (Luminex 100 System; Luminex, Austin, TX, United States) $[45,46]$. Although the Luminex microbead method does not bring unambiguous HLA four-digit typing for all genotypes, the JMDP has validated that this method can identify all HLA alleles with $>0.1 \%$ frequency among the Japanese population [47]. Patients with a prior history of any transplantation have been excluded. The final clinical survey of these patients was finalized by November 1, 2008. The diagnoses were ALL in 145 patients (24\%), AML in 197 (33\%), MDS in 82 (14\%), ML in $64(11 \%), C M L$ in 101 (17\%), and MM in 4 (1\%). Cyclosporine- or tacrolimus-based regimens were administered to all patients for GVHD prophylaxis, and anti-T cell therapy (e.g., anti-thymocyte globulin and ex vivo $\mathrm{T}$ cell depletion) was administered to none of the patients. All patients and donors gave their written informed consent at the time of transplantation to participate in molecular studies of this nature, in accordance with the Declaration of Helsinki. This project was approved by the Institutional Review Boards of Aichi Medical University School of Medicine (2017-M002) and Kanazawa University, as well as the JMDP.

\subsection{HO-1 Genotyping}

The genotypes of HO-1 rs2071746 were determined using the TaqMan allelic discrimination method, as previously reported [20]. The genotyping assay was done in 96 well PCR plates, using specific TaqMan probes for the HO-1 gene single nucleotide variation rs2071746 (C_15869717_10), and in a StepOnePlus Real-Time PCR system (Applied Biosystems, Foster City, CA, United States).

\subsection{Data Management and Statistical Analysis}

The JMDP collected data using a standardized report form [48,49]. Follow-up reports were submitted at 100 days, 1 year, and then annually after transplantation. The pre-transplant cytomegalovirus (CMV) serostatus was routinely checked in the patients only, and not in the donors. Engraftment was defined by an absolute neutrophil count of $>0.5 \times 10^{9} / \mathrm{L}$ for at least three consecutive days. The outcome classification, including GVHD, did not change over time in the current study. After collecting the data, acute and chronic GVHD were diagnosed and graded based on conventionally 
defined criteria [50,51] —namely, acute GVHD was defined as GVHD that developed within the first 100 days post-transplant, while the manifestations of GVHD occurring after day 100 were classified as chronic GVHD. The data using the updated criteria for the assessment of GVHD [52,53] were unavailable in the present cohort. The OS rate was defined as the number of days from transplantation to death from any cause. The DFS rate was defined as the number of days from transplantation to death from any cause or disease relapse or disease progression. Disease relapse was defined as the number of days from transplantation to disease relapse or disease progression. Transplant-related mortality (TRM) was defined as death without relapse. ALL patients who were alive at the last follow-up date were censored. The data on the causative microbes of infections, supportive care (including prophylaxis for infection and therapy for GVHD given on an institutional basis), and postmortem change in the cause of death were unavailable for this cohort.

The analysis was performed with Easy R (EZR) [54], which is a graphical user interface based on the R software program (The R Foundation for Statistical Computing, Vienna, Austria). The probability of OS was calculated using the Kaplan-Meier model and compared using the log-rank test. The probabilities of TRM, relapse, acute/chronic GVHD, and each cause of death were compared using the Gray test [55], and analyzed using a cumulative incidence model [56], considering relapse, death without relapse, death without acute GVHD, death without chronic GVHD, and death without each cause as respective competing risks.

OS, TRM, relapse, grades $2-4$ acute GVHD, grades 3-4 acute GVHD, and chronic GVHD were calculated by using a multivariate Cox method and stepwise selection at a significance level of $5 \%$ to evaluate the HRs associated with the HO-1 genotype. The variables included the recipient's age at the time of transplantation, sex, pre-transplant CMV serostatus, disease characteristics (disease type, disease lineage, and disease risk at transplant), transplant characteristics (conventional or reduced-intensity conditioning) [57], donor characteristics (age, sex, sex compatibility, and ABO compatibility), cyclosporine versus tacrolimus, total nucleated cell counts harvested per recipient weight (TNC), and year of transplantation. We used the median value as the cutoff point regarding continuous variables. The independence of the variables used in the multivariate models was confirmed. The chi-squared test and Mann-Whitney test were used to compare between two groups. The Hardy-Weinberg equilibrium for the HO-1 gene variation was tested using the Haploview program [58]. For both the univariate and multivariate analyses, two-tailed $p$ values of $<0.05$ were considered to indicate statistical significance.

\section{Conclusions}

The findings of the present study suggested that the donor HO-1 rs2071746 A/A or A/T genotype in the promoter region, which is expected to be highly inducible by HO-1, may improve survival outcomes in patients with high-risk hematologic malignancies who are undergoing unrelated BMT. HO-1 rs2071746 genotyping in donors may therefore be a useful tool for evaluating pre-transplantation risk factors in patients with high-risk diseases that can form a basis for the appropriate tailoring transplantation strategies. Considering the plausible functional roles of this $\mathrm{HO}-1$ promoter SNP, it may be a candidate for future prophylactic and therapeutic strategies for complications after allo-HSCT for high-risk patients. Further studies are needed to confirm whether the findings of the present study can be extended to other stem cell sources or HLA-incompatible transplantation, as well as to the other ethnic groups.

Supplementary Materials: The following are available online at http://www.mdpi.com/2072-6694/12/2/424/s1. Figure S1: The Kaplan-Meier analysis of the overall survival rates (A) and the disease-free survival rates (B) after transplantation, according to the donor HO-1 genotype in patients with standard-risk disease. Solid lines represent the donor A/A or A/T genotype. Dashed lines represent the donor T/T genotype. An asterisk denotes statistical significance $(p<0.05)$. In the standard-risk disease group, the donor genotype had no significant effect on the transplant outcomes, Table S1: The results of the univariate analysis of the association between the HO-1 genotype and the clinical outcomes after transplantation (first part), Table S2: The results of the univariate analysis of the association between the HO-1 genotype and the clinical outcomes after transplantation (second part). 
Author Contributions: A.T. and E.M. designed the study. T.H. performed the experimental analyses under instruction by S.M., T.H. performed the statistical analysis, which S.M., K.U., and A.T. supported. T.H. and A.T. wrote the paper. I.H., J.L.E., Y.M., Y.K., M.O., K.K., T.F., N.D., K.M., T.M., S.N. contributed to data collection and sample management. All authors have read and agreed to the published version of the manuscript.

Funding: This study was supported by grants from the Ministry of Education, Culture, Sports and Technology of Japan, as well as the Ministry of Health, Labor and Welfare of Japan.

Acknowledgments: The authors thank all of the Japan Marrow Donor Program (JMDP) transplant teams who provided valuable assistance in caring for the patients and donors investigated in this study.

Conflicts of Interest: The authors declare no conflict of interest.

\section{References}

1. Biedermann, B.C.; Sahner, S.; Gregor, M.; Tsakiris, D.A.; Jeanneret, C.; Pober, J.S.; Gratwohl, A. Endothelial injury mediated by cytotoxic $\mathrm{T}$ lymphocytes and loss of microvessels in chronic graft versus host disease. Lancet 2002, 359, 2078-2083. [CrossRef]

2. Carreras, E.; Diaz-Ricart, M. The role of the endothelium in the short-term complications of hematopoietic SCT. Bone Marrow Transplant 2011, 46, 1495-1502. [CrossRef] [PubMed]

3. Cooke, K.R.; Jannin, A.; Ho, V. The contribution of endothelial activation and injury to end-organ toxicity following allogeneic hematopoietic stem cell transplantation. Biol. Blood Marrow Transplant. J. Am. Soc. Blood Marrow Transplant. 2008, 14, 23-32. [CrossRef] [PubMed]

4. Pagliuca, S.; Michonneau, D.; Sicre de Fontbrune, F.; Sutra Del Galy, A.; Xhaard, A.; Robin, M.; Peffault de Latour, R.; Socie, G. Allogeneic reactivity-mediated endothelial cell complications after HSCT: A plea for consensual definitions. Blood Adv. 2019, 3, 2424-2435. [CrossRef] [PubMed]

5. Rodrigues-Diez, R.; Gonzalez-Guerrero, C.; Ocana-Salceda, C.; Rodrigues-Diez, R.R.; Egido, J.; Ortiz, A.; Ruiz-Ortega, M.; Ramos, A.M. Calcineurin inhibitors cyclosporine A and tacrolimus induce vascular inflammation and endothelial activation through TLR4 signaling. Sci. Rep. 2016, 6, e27915. [CrossRef]

6. Schmid, P.M.; Bouazzaoui, A.; Doser, K.; Schmid, K.; Hoffmann, P.; Schroeder, J.A.; Riegger, G.A.; Holler, E.; Endemann, D.H. Endothelial dysfunction and altered mechanical and structural properties of resistance arteries in a murine model of graft-versus-host disease. Biol. Blood Marrow Transplant. J. Am. Soc. Blood Marrow Transplant. 2014, 20, 1493-1500. [CrossRef]

7. Maines, M.D. Heme oxygenase: Function, multiplicity, regulatory mechanisms, and clinical applications. FASEB J. 1988, 2, 2557-2568. [CrossRef]

8. Bauer, I.; Raupach, A. The Role of Heme Oxygenase-1 in Remote Ischemic and Anesthetic Organ Conditioning. Antioxidants 2019, 8, 403. [CrossRef]

9. Willis, D.; Moore, A.R.; Frederick, R.; Willoughby, D.A. Heme oxygenase: A novel target for the modulation of the inflammatory response. Nat. Med. 1996, 2, 87-90. [CrossRef]

10. Yachie, A.; Niida, Y.; Wada, T.; Igarashi, N.; Kaneda, H.; Toma, T.; Ohta, K.; Kasahara, Y.; Koizumi, S. Oxidative stress causes enhanced endothelial cell injury in human heme oxygenase-1 deficiency. J. Clin. Investig. 1999, 103, 129-135. [CrossRef]

11. Maruyama, K.; Morishita, E.; Yuno, T.; Sekiya, A.; Asakura, H.; Ohtake, S.; Yachie, A. Carbon monoxide (CO)-releasing molecule-derived CO regulates tissue factor and plasminogen activator inhibitor type 1 in human endothelial cells. Thromb. Res. 2012, 130, 188-193. [CrossRef] [PubMed]

12. Otterbein, L.E.; Bach, F.H.; Alam, J.; Soares, M.; Lu, H.T.; Wysk, M.; Davis, R.J.; Flavell, R.A.; Choi, A.M. Carbon monoxide has anti-inflammatory effects involving the mitogen-activated protein kinase pathway. Nat. Med. 2000, 6, e422. [CrossRef] [PubMed]

13. Brouard, S.; Otterbein, L.E.; Anrather, J.; Tobiasch, E.; Bach, F.H.; Choi, A.M.; Soares, M.P. Carbon monoxide generated by heme oxygenase 1 suppresses endothelial cell apoptosis. J. Exp. Med. 2000, 192, 1015-1026. [CrossRef] [PubMed]

14. Pan, T.; Qi, J.; You, T.; Han, S.; Yang, L.; Miao, W.; Wu, D.; Ruan, C.; Zhu, L.; Han, Y. Circulating Heme Oxygenase-1 and Complement Activation in Transplant-Associated Thrombotic Microangiopathy. Biol. Blood Marrow Transplant. J. Am. Soc. Blood Marrow Transplant. 2019, 25, 1486-1491. [CrossRef] [PubMed] 
15. Piantadosi, C.A.; Withers, C.M.; Bartz, R.R.; MacGarvey, N.C.; Fu, P.; Sweeney, T.E.; Welty-Wolf, K.E.; Suliman, H.B. Heme oxygenase-1 couples activation of mitochondrial biogenesis to anti-inflammatory cytokine expression. J. Biol. Chem. 2011, 286, 16374-16385. [CrossRef]

16. Stocker, R.; Yamamoto, Y.; McDonagh, A.F.; Glazer, A.N.; Ames, B.N. Bilirubin is an antioxidant of possible physiological importance. Science 1987, 235, 1043-1046. [CrossRef]

17. BioGPS. HO-1 (HMOX1) Gene. Available online: http://ds.biogps.org/?dataset=GSE1133\&gene=3162 (accessed on 17 October 2019).

18. Ono, K.; Goto, Y.; Takagi, S.; Baba, S.; Tago, N.; Nonogi, H.; Iwai, N. A promoter variant of the heme oxygenase-1 gene may reduce the incidence of ischemic heart disease in Japanese. Atherosclerosis 2004, 173, 315-319. [CrossRef]

19. Buis, C.I.; van der Steege, G.; Visser, D.S.; Nolte, I.M.; Hepkema, B.G.; Nijsten, M.; Slooff, M.J.; Porte, R.J. Heme oxygenase-1 genotype of the donor is associated with graft survival after liver transplantation. Am. J. Transplant. Off. J. Am. Soc. Transplant. Am. Soc. Transpl. Surg. 2008, 8, 377-385. [CrossRef]

20. Espinoza, J.L.; Takami, A.; Onizuka, M.; Sao, H.; Akiyama, H.; Miyamura, K.; Okamoto, S.; Inoue, M.; Kanda, Y.; Ohtake, S.; et al. NKG2D gene polymorphism has a significant impact on transplant outcomes after HLA-fully-matched unrelated bone marrow transplantation for standard risk hematologic malignancies. Haematologica 2009, 94, 1427-1434. [CrossRef]

21. Uchino, K.; Mizuno, S.; Sato-Otsubo, A.; Nannya, Y.; Mizutani, M.; Horio, T.; Hanamura, I.; Espinoza, J.L.; Onizuka, M.; Kashiwase, K.; et al. Toll-like receptor genetic variations in bone marrow transplantation. Oncotarget 2017, 8, 45670-45686. [CrossRef]

22. Nomoto, H.; Takami, A.; Espinoza, J.L.; Onizuka, M.; Kashiwase, K.; Morishima, Y.; Fukuda, T.; Kodera, Y.; Doki, N.; Miyamura, K.; et al. Recipient ADAMTS13 Single-Nucleotide Polymorphism Predicts Relapse after Unrelated Bone Marrow Transplantation for Hematologic Malignancy. Int. J. Mol. Sci. 2019, $20,214$. [CrossRef] [PubMed]

23. Horio, T.; Mizuno, S.; Uchino, K.; Mizutani, M.; Hanamura, I.; Espinoza, J.L.; Onizuka, M.; Kashiwase, K.; Morishima, Y.; Fukuda, T.; et al. The recipient CCR5 variation predicts survival outcomes after bone marrow transplantation. Transpl. Immunol. 2017, 42, 34-39. [CrossRef] [PubMed]

24. Uchino, K.; Mizuno, S.; Mizutani, M.; Horio, T.; Hanamura, I.; Espinoza, J.L.; Matsuo, K.; Onizuka, M.; Kashiwase, K.; Morishima, Y.; et al. Toll-like receptor 1 variation increases the risk of transplant-related mortality in hematologic malignancies. Transpl. Immunol. 2016, 38, 60-66. [CrossRef] [PubMed]

25. Nomoto, H.; Takami, A.; Espinoza, J.L.; Matsuo, K.; Mizuno, S.; Onizuka, M.; Kashiwase, K.; Morishima, Y.; Fukuda, T.; Kodera, Y.; et al. A donor thrombomodulin gene variation predicts graft-versus-host disease development and mortality after bone marrow transplantation. Int. J. Hematol. 2015, 102, 460-470. [CrossRef]

26. Takami, A. Role of non-HLA gene polymorphisms in graft-versus-host disease. Int. J. Hematol. 2013, 98, 309-318. [CrossRef] [PubMed]

27. Arai, Y.; Kondo, T.; Shigematsu, A.; Tanaka, J.; Ohashi, K.; Fukuda, T.; Kawakita, T.; Mori, T.; Hoshino, T.; Onizuka, M.; et al. Increased non-relapse mortality due to high-dose cytarabine plus CY/TBI in BMT/PBSCT for acute lymphoblastic leukaemia in adults. Br. J. Haematol. 2017, 178, 106-111. [CrossRef]

28. Kernan, N.A.; Bartsch, G.; Ash, R.C.; Beatty, P.G.; Champlin, R.; Filipovich, A.; Gajewski, J.; Hansen, J.A.; Henslee-Downey, J.; McCullough, J.; et al. Analysis of 462 transplantations from unrelated donors facilitated by the National Marrow Donor Program. N. Engl. J. Med. 1993, 328, 593-602. [CrossRef]

29. Shimoni, A.; Labopin, M.; Savani, B.; Byrne, M.; Volin, L.; Finke, J.; Niederwieser, D.; Ehninger, G.; Blaise, D.; Beelen, D.; et al. Comparable Long-Term Outcome after Allogeneic Stem Cell Transplantation from Sibling and Matched Unrelated Donors in Patients with Acute Myeloid Leukemia Older Than 50 Years: A Report on Behalf of the Acute Leukemia Working Party of the European Society for Blood and Marrow Transplantation. Biol. Blood Marrow Transplant. J. Am. Soc. Blood Marrow Transplant. 2019, 25, 2251-2260. [CrossRef]

30. HapMap Data of Japanese in rs2071746. Available online: https://www.ncbi.nlm.nih.gov/projects/SNP/snp_ ss.cgi?ss=ss8295263 (accessed on 26 January 2020).

31. Kovtunovych, G.; Ghosh, M.C.; Ollivierre, W.; Weitzel, R.P.; Eckhaus, M.A.; Tisdale, J.F.; Yachie, A.; Rouault, T.A. Wild-type macrophages reverse disease in heme oxygenase 1-deficient mice. Blood 2014, 124, 1522-1530. [CrossRef]

32. Calay, D.; Mason, J.C. The multifunctional role and therapeutic potential of HO-1 in the vascular endothelium. Antioxid. Redox Signal. 2014, 20, 1789-1809. [CrossRef] 
33. Gerbitz, A.; Ewing, P.; Wilke, A.; Schubert, T.; Eissner, G.; Dietl, B.; Andreesen, R.; Cooke, K.R.; Holler, E. Induction of heme oxygenase-1 before conditioning results in improved survival and reduced graft-versus-host disease after experimental allogeneic bone marrow transplantation. Biol. Blood Marrow Transplant. J. Am. Soc. Blood Marrow Transplant. 2004, 10, 461-472. [CrossRef] [PubMed]

34. Askenazi, D.J.; Halloran, B.; Patil, N.; Keeling, S.; Saeidi, B.; Koralkar, R.; Ambalavanan, N. Genetic polymorphisms of heme-oxygenase 1 (HO-1) may impact on acute kidney injury, bronchopulmonary dysplasia, and mortality in premature infants. Pediatric Res. 2015, 77, 793-798. [CrossRef] [PubMed]

35. Nitti, M.; Piras, S.; Marinari, U.M.; Moretta, L.; Pronzato, M.A.; Furfaro, A.L. HO-1 Induction in Cancer Progression: A Matter of Cell Adaptation. Antioxidants 2017, 6, 29. [CrossRef] [PubMed]

36. Salerno, L.; Romeo, G.; Modica, M.N.; Amata, E.; Sorrenti, V.; Barbagallo, I.; Pittala, V. Heme oxygenase-1: A new druggable target in the management of chronic and acute myeloid leukemia. Eur. J. Med. Chem. 2017, 142, 163-178. [CrossRef] [PubMed]

37. Wei, S.; Wang, Y.; Chai, Q.; Fang, Q.; Zhang, Y.; Lu, Y.; Wang, J. Over-expression of heme oxygenase-1 in peripheral blood predicts the progression and relapse risk of chronic myeloid leukemia. Chin. Med. J. 2014, 127, 2795-2801.

38. Bernasconi, P.; Borsani, O. Immune Escape after Hematopoietic Stem Cell Transplantation (HSCT): From Mechanisms to Novel Therapies. Cancers 2019, 12, 69. [CrossRef]

39. Kollgaard, T.; Kornblit, B.; Petersen, J.; Klausen, T.W.; Mortensen, B.K.; Braendstrup, P.; Sengelov, H.; Hogdall, E.; Muller, K.; Vindelov, L.; et al. (GT)n Repeat Polymorphism in Heme Oxygenase-1 (HO-1) Correlates with Clinical Outcome after Myeloablative or Nonmyeloablative Allogeneic Hematopoietic Cell Transplantation. PLoS ONE 2016, 11, e0168210. [CrossRef]

40. Narita, M.; Hatano, E.; Ikai, I.; Miyagawa-Hayashino, A.; Yanagida, A.; Nagata, H.; Asechi, H.; Taura, K.; Uemoto, S. A phosphodiesterase III inhibitor protects rat liver from sinusoidal obstruction syndrome through heme oxygenase-1 induction. Ann. Surg. 2009, 249, 806-813. [CrossRef]

41. Yu, M.; Wang, J.; Fang, Q.; Liu, P.; Chen, S.; Zhe, N.; Lin, X.; Zhang, Y.; Zhao, J.; Zhou, Z. High expression of heme oxygenase- 1 in target organs may attenuate acute graft-versus-host disease through regulation of immune balance of TH17/Treg. Transpl. Immunol. 2016, 37, 10-17. [CrossRef]

42. Yakushijin, K.; Atsuta, Y.; Doki, N.; Yokota, A.; Kanamori, H.; Miyamoto, T.; Ohwada, C.; Miyamura, K.; Nawa, Y.; Kurokawa, M.; et al. Sinusoidal obstruction syndrome after allogeneic hematopoietic stem cell transplantation: Incidence, risk factors and outcomes. Bone Marrow Transplant. 2016, 51, 403-409. [CrossRef]

43. Shimoni, A.; Yeshurun, M.; Hardan, I.; Avigdor, A.; Ben-Bassat, I.; Nagler, A. Thrombotic microangiopathy after allogeneic stem cell transplantation in the era of reduced-intensity conditioning: The incidence is not reduced. Biol. Blood Marrow Transplant. J. Am. Soc. Blood Marrow Transplant. 2004, 10, 484-493. [CrossRef] [PubMed]

44. Tatekawa, S.; Kohno, A.; Ozeki, K.; Watamoto, K.; Ueda, N.; Yamaguchi, Y.; Kobayashi, T.; Yokota, I.; Teramukai, S.; Taniwaki, M.; et al. A Novel Diagnostic and Prognostic Biomarker Panel for Endothelial Cell Damage-Related Complications in Allogeneic Transplantation. Biol. Blood Marrow Transplant. J. Am. Soc. Blood Marrow Transplant. 2016, 22, 1573-1581. [CrossRef] [PubMed]

45. Kawase, T.; Morishima, Y.; Matsuo, K.; Kashiwase, K.; Inoko, H.; Saji, H.; Kato, S.; Juji, T.; Kodera, Y.; Sasazuki, T.; et al. High-risk HLA allele mismatch combinations responsible for severe acute graft-versus-host disease and implication for its molecular mechanism. Blood 2007, 110, 2235-2241. [CrossRef]

46. Sasazuki, T.; Juji, T.; Morishima, Y.; Kinukawa, N.; Kashiwabara, H.; Inoko, H.; Yoshida, T.; Kimura, A.; Akaza, T.; Kamikawaji, N.; et al. Effect of matching of class I HLA alleles on clinical outcome after transplantation of hematopoietic stem cells from an unrelated donor. Japan Marrow Donor Program. N. Engl. J. Med. 1998, 339, 1177-1185. [CrossRef] [PubMed]

47. Morishima, Y.; Yabe, T.; Matsuo, K.; Kashiwase, K.; Inoko, H.; Saji, H.; Yamamoto, K.; Maruya, E.; Akatsuka, Y.; Onizuka, M.; et al. Effects of HLA allele and killer immunoglobulin-like receptor ligand matching on clinical outcome in leukemia patients undergoing transplantation with T-cell-replete marrow from an unrelated donor. Biol. Blood Marrow Transplant. J. Am. Soc. Blood Marrow Transplant. 2007, 13, 315-328. [CrossRef]

48. Atsuta, Y. Introduction of Transplant Registry Unified Management Program 2 (TRUMP2): Scripts for TRUMP data analyses, part I (variables other than HLA-related data). Int. J. Hematol. 2016, 103, 3-10. [CrossRef] [PubMed] 
49. Kanda, J. Scripts for TRUMP data analyses. Part II (HLA-related data): Statistical analyses specific for hematopoietic stem cell transplantation. Int. J. Hematol. 2016, 103, 11-19. [CrossRef]

50. Przepiorka, D.; Weisdorf, D.; Martin, P.; Klingemann, H.G.; Beatty, P.; Hows, J.; Thomas, E.D. 1994 Consensus Conference on Acute GVHD Grading. Bone Marrow Transplant. 1995, 15, 825-828.

51. Shulman, H.M.; Sullivan, K.M.; Weiden, P.L.; McDonald, G.B.; Striker, G.E.; Sale, G.E.; Hackman, R.; Tsoi, M.S.; Storb, R.; Thomas, E.D. Chronic graft-versus-host syndrome in man. A long-term clinicopathologic study of 20 Seattle patients. Am. J. Med. 1980, 69, 204-217. [CrossRef]

52. Filipovich, A.H.; Weisdorf, D.; Pavletic, S.; Socie, G.; Wingard, J.R.; Lee, S.J.; Martin, P.; Chien, J.; Przepiorka, D.; Couriel, D.; et al. National Institutes of Health consensus development project on criteria for clinical trials in chronic graft-versus-host disease: I. Diagnosis and staging working group report. Biol. Blood Marrow Transplant. J. Am. Soc. Blood Marrow Transplant. 2005, 11, 945-956. [CrossRef]

53. Rowlings, P.A.; Przepiorka, D.; Klein, J.P.; Gale, R.P.; Passweg, J.R.; Henslee-Downey, P.J.; Cahn, J.Y.; Calderwood, S.; Gratwohl, A.; Socie, G.; et al. IBMTR Severity Index for grading acute graft-versus-host disease: Retrospective comparison with Glucksberg grade. Br. J. Haematol. 1997, 97, 855-864. [CrossRef] [PubMed]

54. Kanda, Y. Investigation of the freely available easy-to-use software 'EZR' for medical statistics. Bone Marrow Transplant. 2013, 48, 452-458. [CrossRef] [PubMed]

55. Gooley, T.A.; Leisenring, W.; Crowley, J.; Storer, B.E. Estimation of failure probabilities in the presence of competing risks: New representations of old estimators. Stat. Med. 1999, 18, 695-706. [CrossRef]

56. Scrucca, L.; Santucci, A.; Aversa, F. Competing risk analysis using R: An easy guide for clinicians. Bone Marrow Transplant. 2007, 40, 381-387. [CrossRef]

57. Giralt, S.; Ballen, K.; Rizzo, D.; Bacigalupo, A.; Horowitz, M.; Pasquini, M.; Sandmaier, B. Reduced-intensity conditioning regimen workshop: Defining the dose spectrum. Report of a workshop convened by the center for international blood and marrow transplant research. Biol. Blood Marrow Transplant. J. Am. Soc. Blood Marrow Transplant. 2009, 15, 367-369. [CrossRef]

58. Kim, D.H.; Jung, H.D.; Lee, N.Y.; Sohn, S.K. Single nucleotide polymorphism of CC chemokine ligand 5 promoter gene in recipients may predict the risk of chronic graft-versus-host disease and its severity after allogeneic transplantation. Transplantation 2007, 84, 917-925. [CrossRef]

(C) 2020 by the authors. Licensee MDPI, Basel, Switzerland. This article is an open access article distributed under the terms and conditions of the Creative Commons Attribution (CC BY) license (http://creativecommons.org/licenses/by/4.0/). 